\title{
AN EVALUATION OF AIRPORT WAYFINDING AND SIGNAGE ON SENIOR DRIVER BEHAVIOUR AND SAFETY OF AIRPORT ROAD ACCESS DESIGN
}

Nur Khairiel Anuar, Romano Pagliari; Richard Moxon ${ }^{1}$

\begin{abstract}
The purpose of this study was to investigate the impact of different wayfinding provision on senior driving behaviour and road safety. A car driving simulator was used to model scenarios of differing wayfinding complexity and road design. Three scenario types were designed consisting of 3.8 miles of airport road. Wayfinding complexity varied due to differing levels of road-side furniture. Experienced car drivers were asked to drive simulated routes. Forty drivers in the age ranges: 50 to 54,55 to 59 and those aged over 60 were selected to perform the study. Participants drove for approximately 20 minutes to complete the simulated driving. The driver performance was compared between age groups. Results were analysed by Mean, Standard Deviation and ANOVA Test, and discussed with reference to the use of the driving simulator. The ANOVA confirmed that age group has a correlation between road design complexity, driving behaviour and driving errors.
\end{abstract}

\section{KEYWORDS}

Airport; Senior driver; Driving behaviour; Road safety; Simulation

${ }^{1}$ Centre for Air Transport Management, Cranfield University Cranfield, Bedfordshire, UK n.anuar@cranfield.ac.uk ${ }^{2}$ R.Pagliari@cranfield.ac.uk ${ }^{3}$ r.moxon@cranfield.ac.uk 


\section{INTRODUCTION}

The importance, functions and design criteria of wayfinding and traffic signs are essential in designing a complete airport road access. Poor wayfinding provision discourages drivers and is not directed towards understanding the concepts or practice (Burns, 1998; Darken \& Sibert, 1996; Montello \& Sas, 2006) in airport areas. Previous literatures (Beijer, Smiley, \& Eizenman, 2004; Burns, 1998; Charles \& Haddad, 2007; Darken \& Sibert, 1996; Findlay \& Southwell, 2004; Fuller, 2002; J. R. Harding et al., 2011; J. Harding, 2012; Raubal \& Egenhofer, 1998; Raubal \& Worboys, 1999; Raubal, 2001; Smiley, Houghton, \& Philp, 2004) discussed wayfinding and signage as a supporting role of the urban landscape and architecture. The design of signage, wayfinding, roads and the facilities provided for airport building is very important to all travellers, as airports contribute to high growth economies and affect the environment and quality of life.

The debate concerning visual effects caused by the proliferation of signs and wayfinding along roads has led to considerable discussion by transport planners. This is a major problem which threatens to become greater as more and more elements are added to roadside landscapes; much of the road furniture is not there to help with road safety and it is understandable and right that transport authorities consider this one of their main priorities (Transport Scotland, 2006). Ineffective signage around airport areas distracts from wayfinding. Harding (2012) stated that many airports have not established the concept of 'simple, functional and less is more' for airport signage systems. He suggests a simple wayfinding and sign message could help reduce the overall cost of poor signage systems which make them less attractive and competitive than neighbourhood airports (Alhussein, 2011; J. R. Harding et al., 2011). In many cases, drivers experience most difficulty in understanding the complete wayfinding process, resulting in distraction while driving (Bhise \& Rockwell, 1973; May, Ross, \& Bayer, 2005) in airport areas. This distraction (e.g. too much advertising signage) increases drivers' confusion and road accidents (Mitchell, 2010; Wener \& Kaminoff, 1983) in airport road access.

Senior drivers and airport road access design has been discussed in section 2 and 3 . The methodology of this paper was explained in section 4, followed by results in section 5 and discussion in section 6. Conclusion, limitation and future research of this study has been described in section 7, 8 and 9, respectively. 


\section{SENIOR DRIVERS AND AIRPORT ROAD ACCESS}

There are challenges in defining when an individual becomes an elderly or senior citizen. Most developed countries set the age of senior citizen at 65 years old, but in other regions such as Africa, the "senior" threshold is much lower at 50 years (WHO, 2016). Orimo et al. (2006) stated that with recent technology in the medical and health science industry, the average lifespan has increased rapidly, thus, such a definition of elderly to simply include all persons over 65 years might be no longer appropriate for this era with a life expectancy of 80 years. WHO (2016) agreed that a definition of senior is arbitrary and introduces additional problems of data comparability across nations. For example, the MDS Project ${ }^{2}$ collaborators agreed at the 200 Harare MDS Workshop to use the chronological age of 60 years as a guide for the working definition of "old"; however, this definition was revisited (i.e. "older" was set at the age of 50 years) due to it not taking into account the real situation of older persons in developing countries. In addition, British Senior Insurance ${ }^{3}$, the minimum age range of senior citizen has been set to 50 years old in order to have the Lifetime Payment Guarantee policy.

WHO (2011) reported that the number of people aged 65 and over is projected to grow from an estimated 524 million in 2010 to nearly 1.5 billion in 2050, with most of the increase in developing countries. Driving represents the most significant mode of transportation for senior drivers in terms of mode share and distance travelled (O'Hern \& Oxley, 2015). With an increasing ageing population throughout much of the developed world combined with increasing life expectancies, it is necessary to understand travel behaviour, mobility and safety implications of active transport used (i.e. the private car) on airport road access (Budd, Ison, \& Ryley, 2011; Chang, 2013; Tam, Lam, \& Lo, 2008) by senior drivers. Understanding senior drivers' mobility and accessibility needs was crucial to ensure that a specific requirement of road access systems is fully provided (Alsnih \& Hensher, 2003). The output of this research could be significantly beneficial to airport management, road sign design professionals and airport users, including senior drivers, in the future.

Senior drivers are a large and increasing proportion of the population (National Institute on Aging et al., 2011; RoSPA, 2010). In 2014, 21,490 casualties were reported as being senior drivers in the UK (Department for Transport, 2015a, 2015c). Senior drivers are commonly

\footnotetext{
2 The workshop was convened on behalf of the World Health Organization's Minimum Data Set (MDS) Project on Ageing and Older Adults in sub-Saharan Africa, by South African MDS Project collaborators Monica Ferreira (Institute of Ageing in Africa, University of Cape Town) and Craig Schwabe (Geographic Information Systems Centre (GIS), Human Sciences Research Council).

3 https://www.britishseniors.co.uk/over-50-insurance/
} 
involved in road accidents often because of misjudged speed or distance of other vehicles or failing to see a hazard (Department for Transport, 2015b; RoSPA, 2010).

Senior drivers are likely to drive to the airport due to carrying extra luggage and preferring more time spent in the vehicle (Ashford, Mumayiz, \& Wright, 2011; Chang, 2013). DfT (2015d) reported that private car is the preferred transportation mode to reach the airport; i.e. Manchester Airport (57 per cent), London Luton Airport (54 per cent), and Gatwick Airport (43 per cent). Public transport is the second preferred transportation mode at Stansted Airport (39 per cent) and London Heathrow International Airport (29 per cent). With a current ageing population throughout much of the developed world, there is an imminent need to understand the current transportation requirements (Alsnih \& Hensher, 2003; O'Hern \& Oxley, 2015) of senior drivers, and to ensure sustained safe mobility and comfort on airport road access (Chang, 2013; Chebli \& Mahmassani, 2002; O'Hern \& Oxley, 2015). The results confirmed that the wayfinding has importance for the promotion of road safety.

The research focuses on the senior drivers as this segment of the travel market is becoming increasingly important in many countries. Many airports report that the proportion of elderly passengers using their facilities has increased and is predicted to rise further in the years ahead. An improvement on airport road access wayfinding, road safety and comfort for senior drivers should be considered by airport management, road sign design professionals and road authorities.

\section{DRIVING BEHAVIOUR AND ROAD SAFETY OF SENIOR DRIVERS}

Underlying health conditions, and some types of medication taken to treat those problems, are common factors in accidents involving senior drivers. Indeed, a proportion of senior driver fatalities occur when a senior driver dies of natural causes while driving, and so their vehicle immediately crashes. Senior drivers are commonly involved in collisions at junctions, because of misjudging the speed or distance of other vehicles or failing to see a hazard (Devlin \& McGillivray, 2016). They are likely to drive slowly and in some circumstances they probably stop driving completely, particularly when approaching junctions. Although this may appear to be safe behavioural adaptation, their speed reduction can occur without consideration of traffic regulations. However, not all senior drivers do this, and there is little guidance for drivers about it. A major deterrent to self-regulation or stopping driving is the lack, or perceived lack, of viable alternatives to the car. 
Elander et al. (1993) stated that the relationship between drivers' skills, behaviour and accident involvement is complex. Safe driving is clearly a complex skill in which various cognitive processes such as perception, attention and motor control are involved (Jamson \& Merat, 2005). Elander, Jamson and Merat found that the association between drivers' skills and crash involvement were related through the changes in the way drivers are trained and tested.

Senior drivers' behaviour and safety are connected to the driving abilities and willingness to take risks on the road. The contrast between the safety performances expected of road transport and the management of all other risks is stark, not least when compared with other transport modes (e.g. rail and sea) in terms of fatality and the total of all casualty categories (Department for Transport, 2015c; Evans, 2003; Gayle, 2014). Senior drivers felt that their driving experience skills and driving abilities may not be as good as they once were, which in turn, means that they started to have difficulties in assessing complex problems or high-speed traffic situations and required additional information process time to make a decision (Hassan, King, \& Watt, 2015; IAM, 2010). Driving behaviour that led to risk of road accidents (i.e. failing to look properly, poor turn manoeuvre, speeding, aggressive driving, overtaking and tailgating the car in front, failing to stop for traffic lights, and unable to process information on signs) has appeared as a critical factor of distinguishing crashes involving senior drivers (Department for Transport, 2015c; Elander et al., 1993; Godley, Triggs, \& Fildes, 2004; Mårdh, 2016; Oltedal \& Rundmo, 2006; RoSPA, 2010), which are caused by poor wayfinding on current road designs.

Reported statistics indicate that the risk of an accident increases after the age of 60 up to 70 , and they are no more likely to cause a crash than to be the victim of another road user's mistake. However, drivers over 70 are more likely to be at fault when they crash. CrashMap (2015) reported the high road accidents rate on airport road access; i.e. London Heathrow Airport (LHR) had the highest reported casualties (129 casualties), followed by Gatwick Airport (43 casualties), Edinburgh Airport (39 casualties), Glasgow Airport (26 casualties), Manchester Airport (19 casualties) and London Luton Airport (15 casualties) in 2014.

Road safety plays a fundamental role by decreasing the risk of being involved in an accident. Engineering measures such as a road design can prevent accidents and injuries to senior road users (RoSPA, 2010). RoSPA suggested that due to a higher number of accidents at junctions were involving senior drivers, road planners should redesign areas in which high crash rates are reported. An important aspect of senior drivers' safety is being able to 
accurately identify which drivers are significantly more likely to be involved in crashes, and ultimately to help them give up driving and adapt to life without a car.

\section{METHODOLOGY}

Driving scenarios were scripted within a general-purpose "world" provided by a simulator that included a dual carriageway, with buildings, static objects, pedestrian walk-ways and vegetation. Driving simulation is field experimentation using a model building technique to determine the effects of changes and computer-based simulations (Sekaran, 2003). It was developed to test drivers' performance on a virtual environment of airport road access wayfinding design. Drivers and architectural clues (e.g. signs, maps and buildings) were included in the driving wayfinding simulation (Raubal, 2001). A causal and effect analysis was performed with the control of the researcher in the experimental simulation (Beins \& McCarthy, 2012; Sekaran, 2003) which validated selected research variables of the intended study. As stated by Raubal and Egenhofer (1998), the combination of drivers' choice (decision) and clues (i.e. sign message) in a real world can be measured through virtual simulation.

This research set the minimum age of 50 years as a "senior", and selected 40 senior drivers aged 50 years and above as a sample of the population. The definition of "senior" being aged 50 years and above was set to allow an accepted minimum "older" age (i.e. based on the MDS Workshop case) globally (Kowal, Rao, \& Mathers, 2003). This research, hopefully, could be extended to be applied to other countries for airport road access wayfinding improvements.

\section{a. Scenario Specifics}

The simulated driving was scripted using a Scenario Definition Language (SDL) provided by the STISIM Drive Software Version 2. The authoring software was used to add the necessary objects (e.g. direction and advertisement signs, bollards and pedestrians) and auditory cues which provided the driver with instructions (e.g. "That is the end of the simulation"). Scenarios were scripted within a general purpose of the simulator that was a mixture of dual carriageway, buildings, static objects, pedestrian pavement and vegetation.

Three scenario types were designed to provide a variety of driving scenarios and complexity of the road designs to the airport. The complexity of wayfinding varied to assess the safe driving behaviour on alternative airport road access design. Drivers' decisions and judgement are extremely important while driving especially when they have to make a rapid 
decision or whilst making decisions under pressure at decision points (Casutt, Martin, Keller, \& Jäncke, 2014; Hassan et al., 2015). Drivers need to demonstrate visual scanning of the driving environment. They also must be able to make a quick scan of the signage information. Drivers often will face degrees of pressure and anxiety on journeys to airports in order to ensure that flights are not missed.

Table 1 shows the total number of signs and road furniture in the driving simulation scenarios. We established three scenarios representing different degrees of airport road design complexity.

Table 1: Total number of signs and road furniture in the driving simulation scenarios

\begin{tabular}{|c|c|c|c|c|}
\hline $\begin{array}{c}\text { Road furniture } \\
\text { type }\end{array}$ & $\begin{array}{c}\text { Simulation 1 } \\
(\mathbf{S 1})\end{array}$ & $\begin{array}{c}\text { Simulation 2 } \\
\mathbf{( S 2 )}\end{array}$ & $\begin{array}{c}\text { Simulation 3 } \\
\mathbf{( S 3 )}\end{array}$ & Total \\
\hline Directional sign & 129 & 145 & 160 & 434 \\
\hline Regulatory sign & 8 & 8 & 8 & 24 \\
\hline Warning sign & 36 & 36 & 36 & 108 \\
\hline Advert & 8 & 21 & 28 & 57 \\
\hline Bollard & 68 & 68 & 68 & 204 \\
\hline Traffic light & 2 & 2 & 2 & 6 \\
\hline Pelican beacon & 2 & 2 & 2 & 6 \\
\hline Street light & 45 & 45 & 45 & 135 \\
\hline Pedestrian & 218 & 326 & 513 & 1057 \\
\hline Intersection & 11 & 11 & 11 & 33 \\
\hline Building & 90 & 101 & 111 & 302 \\
\hline Vehicle & 199 & 199 & 199 & 597 \\
\hline Roundabout & 3 & 3 & 3 & 9 \\
\hline Bus stop & 2 & 2 & 2 & 6 \\
\hline Total & $\mathbf{8 2 1}$ & $\mathbf{9 6 9}$ & $\mathbf{1 1 8 8}$ & $\mathbf{2 9 7 8}$ \\
\hline
\end{tabular}

Scenario 1 or 'Less Complex' scenario was designed to be as less busy as possible to test the effect of road design on drivers' wayfinding to the airport. Drivers' behaviour and safety during navigation were also tested. The signage placement and road furniture were included to assess drivers' adaption to the actual airport road design with accurate wayfinding (including signage) provided. Scenario 2 or 'Complex' scenario was designed as a busy road and more complex in terms of road access design and wayfinding (including signage). Curved roads and warning signage were included in order to measure the impact of airport 
road design on drivers' safety and driving behaviour. Multiple signage types (e.g. diamond and rectangle signs) in the simulation design were considered. Scenario 3 or 'More Complex' scenario was designed as a busiest airport road with different types of direction and warning signs (e.g. diamond and rectangle signs), advertisement signs and complexity of airport road design provided with accurate wayfinding systems (including signage).

\section{b. Procedure}

The simulation participants were selected based on convenient sampling and participation in this study was completely voluntary. Convenience sampling is a non-random (nonprobability) sampling technique that involves using whatever participants can conveniently be studied. It is most often used during experiment-based research and is the best way of obtaining basic information in the most efficient way (Sekaran, 2003). Thus, convenient sampling is the most appropriate sampling design for this paper because the collection of information is collated from the population of participants who are conveniently available to provide it.

40 experienced car drivers holding a valid driving license volunteered to take part in the study. The age of drivers ranged from 50 to over 60 with a sample mean age of 59 years. Complete instructions were given before the simulation started. Drivers were instructed to drive to the airport with the aid of wayfinding and signage in the driving scenario. The simulation test was 3.8 miles long for each scenario and took approximately 20 - 30 minutes to complete all three simulations. Participants decided which route to use based on the provided signage and wayfinding systems. The scenario was tested randomly.

\section{c. Data Analysis}

The mean and standard deviation were used in this research as they are the most common descriptive statistics, and a very useful tool of statistical rules, in normal distribution (Beins \& McCarthy, 2012; Robson \& McCartan, 2016; Sekaran, 2003). Beins and McCarthy (2012) stated that ANOVA compares group means to assess the reliability of different means. In this research, ANOVA was used to measure the most prevalent importance of driving behaviour, road safety and the complexity of road design. The ANOVA test measures the differences of the independent variable (e.g. drivers' age group) and the dependent variables (e.g. risk of collision and centreline crossings). The level of significance $(p<0.05)$ was set in this study while $95 \%$ confidence level was selected as a conventionally accepted level (Sekaran, 2003). 


\section{RESULTS}

\section{a. Hypotheses}

Table 2 shows the mapping of research hypotheses, research variables and analysis techniques in the airport road access wayfinding research.

Table 2: Research Hypotheses, Research Variables and Analysis Technique

\begin{tabular}{|l|c|c|}
\hline \multicolumn{1}{|c|}{ Hypotheses } & Study Variables & Analysis Techniques \\
\hline $\begin{array}{l}\text { Ho: Low adverse impact of airport } \\
\text { road access complexity design on } \\
\text { driving behaviour and road safety. }\end{array}$ & $\begin{array}{c}\text { Factors that contribute to } \\
\text { safe driving behaviour and } \\
\text { road safety (IV) }\end{array}$ & $\begin{array}{c}\text { Frequency analysis (Mean } \\
\text { and standard deviation) }\end{array}$ \\
\hline $\begin{array}{l}\mathrm{H}_{1} \text { : High adverse impact of airport } \\
\text { road access complexity design on } \\
\text { driving behaviour and road safety. }\end{array}$ & $\begin{array}{c}\text { Airport road access } \\
\text { wayfinding (DV) }\end{array}$ & ANOVA Test \\
\hline
\end{tabular}

\section{b. Drivers'Age and Gender}

There were a total of 40 respondents who volunteered to participate in this research as a convenience sampling design was applied. Table 3 shows the age group of senior drivers who volunteered as participants in this research.

Table 3: Range of drivers' ages

\begin{tabular}{|c|c|c|c|c|}
\hline & Minimum & Maximum & Mean & Standard Deviation \\
\hline Age & 50 & 71 & 58.60 & 5.31 \\
\hline
\end{tabular}

The minimum and maximum age of the senior drivers are 50 and 71 years old, respectively. Mean and standard deviation of age range was computed as 58.60 and 5.31 , respectively. The mean and SD results revealed that most of the participants were aged in the range of 53 to 63 years. In total, 24 male drivers (60 per cent) and 16 female drivers ( 40 per cent) successfully completed the driving simulation test. The selection of senior drivers' gender was based on convenience sampling and volunteered feedback during invitation timeframe (e.g. 6 months). 


\section{c. Key Factors Influence Senior Driving Behaviour}

Figures 1, 2 and 3 show mean and standard deviation computed for senior drives' age mistakes based on 'Less Complex', 'Complex' and 'More Complex' road design, respectively. The results show that there is a low impact between road design complexity and driving errors. The results also revealed that the road edge excursions was the most mistakes and 'disobeyed' red traffic lights was the lowest mistakes made by senior drivers in all simulated driving scenarios. Senior drivers preferred to drive near to the road edges (or road shoulders), 'too carefully' at the junctions and roundabouts and surprisingly drove too fast in sections of the road that had lower speed limits. This pattern showed that senior drivers are less safe and are exposed to incidents on the road. In the 'Less Complex' wayfinding design (Figure 1), senior drivers were likely to cross the road edge (mean=3.90, SD=2.32), be exposed to the risk of collisions due to driving too close to a vehicle in front (mean=1.43, $\mathrm{SD}=0.81$ ), exceeding the speed limit (mean=0.33, $\mathrm{SD}=0.57$ ), cross the centreline (mean $=0.10, \mathrm{SD}=0.30$ ) and were less aware of red traffic lights (mean=0.05, SD=0.22).

Figure 1: Mean and SD of drivers' age based on 'Less Complex' Scenario

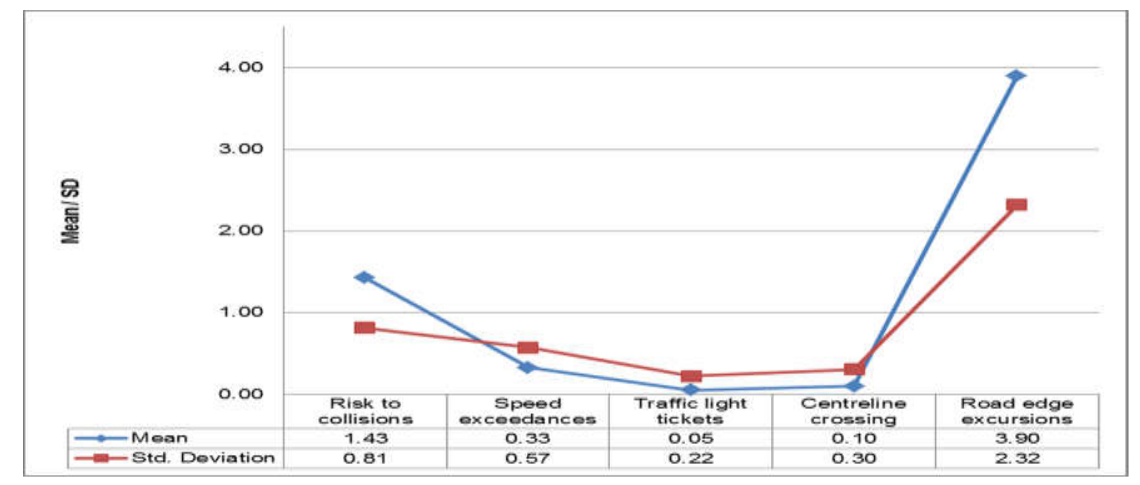

Senior drivers' mistakes during the driving simulation test were recorded. In the 'Complex' wayfinding design (Figure 2), senior drivers were likely to speed and exceed the standard speed limit (mean=0.43, SD=0.84). They preferred to drive close to the kerb, which resulted in road edge excursions (mean $=4.20, S D=4.44$ ).

However, they were likely to cross the centreline of the road lane (mean $=0.15, S D=0.43$ ) when attempting to turn at the next junctions. Tailgating as one of the major contributors to the road accidents could raise the risk of collision (mean=1.48, SD=0.91). Traffic light ticket (mean $=0.03, \mathrm{SD}=0.16$ ) rates were low in the 'Complex' scenario, perhaps because of their experience from the previous simulated driving test. 
Figure 2: Mean and SD of drivers' age based on 'Complex' Scenario

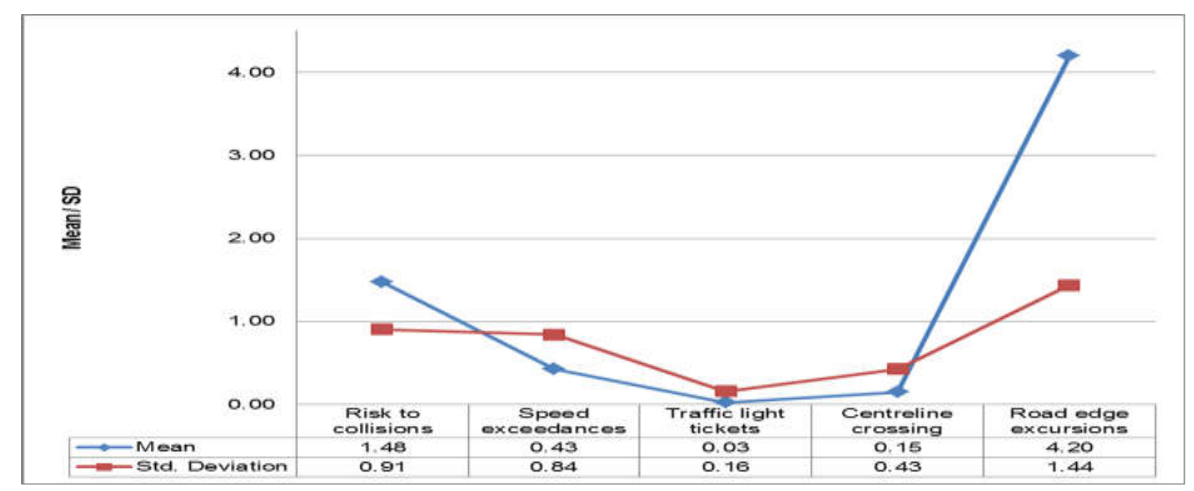

Drivers made more errors in the 'More Complex' wayfinding design (Figure 3); road edge excursions (mean=4.85, SD=1.12), risk to collisions (mean=1.63, SD=0.70), speeding (mean=0.60, SD=1.08), crossing the centreline (mean=0.35, SD=1.48), and less aware of red traffic lights (mean $=0.13, S D=0.33$ ) while performing navigation in this scenario. These five mistakes are the major factors influencing senior driving behaviour and safety on airport road access wayfinding design.

Figure 3: Mean and SD of drivers' age based on 'More Complex' Scenario

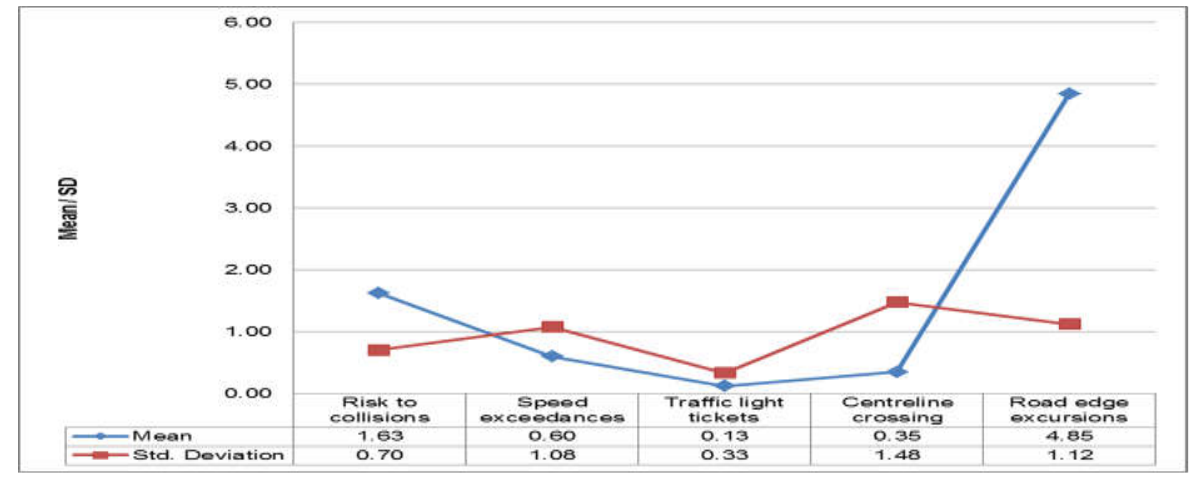

\section{d. The Impact of Airport Road Access Complexity on Driving Behaviour and Road Safety}

Table 4 shows the ANOVA test results of the research parameters. 
Table 4. Summary of Senior Drivers' Mistakes in Simulated Driving

\begin{tabular}{|c|c|c|c|c|c|c|}
\hline \multirow{2}{*}{ Driver's Mistake } & \multicolumn{2}{|c|}{ Simulation 1 } & \multicolumn{2}{c|}{ Simulation 2 } & \multicolumn{2}{c|}{ Simulation 3 } \\
\cline { 2 - 7 } & F & p-value & F & p-value & F & p-value \\
\hline Risk to collisions & 0.928 & 0.405 & 0.727 & 0.490 & 0.158 & 0.855 \\
\hline Speed exceedances & 0.216 & 0.807 & 0.523 & 0.597 & 1.725 & 0.192 \\
\hline Traffic light tickets & 0.849 & 0.436 & 1.177 & 0.319 & 0.720 & 0.493 \\
\hline Centreline crossings & 0.742 & 0.483 & 0.146 & 0.865 & 0.826 & 0.446 \\
\hline Road edge excursions & 0.564 & 0.574 & 1.262 & 0.295 & 1.228 & 0.305 \\
\hline
\end{tabular}

\section{i. Risk of collisions}

The ANOVA result of risk to collisions shows that there was low statistically significant difference between risk of collisions and senior drivers' age group. It shows that senior drivers had no difficulties to reach the airport in Simulation $1(F=0.93, p=0.41)$, Simulation 2 $(F=0.73, p=0.49)$ and Simulation $3(F=0.16, p=0.86)$. Therefore, there is low statistical impact to airport road access wayfinding designs on road safety. Based on Table 4, the highest possibility of senior drivers being exposed to a road accident was in the 'More Complex' (mean=1.63, SD=0.70), followed by 'Complex' (mean=1.48, SD=0.91) and 'Less Complex' (mean=1.43, SD=0.81) scenarios. Senior drivers were observed to drive near to the road edges (especially at the roundabouts), had difficulties in making a fast decision at the decision point (e.g. junctions and approaching signs), and failed to respond to speed limit signs at low speed limit roads. These factors were contributory factors that lead to road collisions.

\section{ii. Speed exceedances}

The ANOVA result shows low significant impact between speed exceedances and age group of senior drivers; Simulation $1(F=0.22, p=0.81)$, Simulation $2(F=0.52, p=0.60)$, and Simulation $3(F=1.73, p=0.19)$. The results in Table 4 revealed that airport road access wayfinding design has low link to senior driving behaviour and safety. Drivers preferred to speed in the 'More Complex' (mean=0.60, SD=1.08) airport road access wayfinding design compared to the other scenarios. Variable speed limit signs were considered in the "More Complex" scenario; however, the results confirmed that the complexity of the airport road access wayfinding design less affect senior drivers' behaviour. Surprisingly, research results revealed that the speeding was controllable in the 'Less Complex' scenario (mean $=0.33$, $\mathrm{SD}=0.57$ ). The 'less busy' and 'cosy' environment led senior drivers to the comfort driving 
without thinking of other tasks. Observation confirmed that senior drivers felt it to be comfortable and easy to navigate to the airport. DfT (2015c) and Oxley et al. (2006) reported that exceeding the speed limit and driving too fast are contributory factors to the accidents and casualties statistics. Exceeding the speed limit was reported in around 16 per cent of fatal accidents in 2014, whereas 8 per cent of fatal accidents were caused by driving too fast. A similar pattern was seen for reported road fatalities where exceeding the speed limit contributed to 17 per cent of fatalities and driving too fast contributed to 8 per cent of fatalities. The road statistics also revealed that 7 per cent of serious accidents and seriously injured casualties were allocated to the categories of exceeding the speed limit and travelling too fast.

\section{iii. Traffic light tickets}

The ANOVA result shows the airport road access wayfinding design has low significant impact on driving behaviour and road safety in terms of traffic light awareness. Senior drivers were less aware of red traffic lights in all scenarios; Simulation $1(F=0.85, p=0.44)$, Simulation $2(\mathrm{~F}=1.18, \mathrm{p}=0.32)$ and Simulation $3(\mathrm{~F}=0.72, \mathrm{p}=0.49)$. Statistical results revealed that senior drivers are more likely to fail to stop at red traffic lights in the 'More Complex' scenario (mean=0.13, SD=0.33) compared to the 'Complex' (mean=0.03, $\mathrm{SD}=0.16)$ and 'Less Complex' (mean $=0.05, \mathrm{SD}=0.22$ ) scenarios.

\section{iv. Centreline crossings}

The ANOVA result shows the senior drivers' age had low impact on road centreline crossing in all scenarios. Drivers are likely to cross the centreline more often in the 'More Complex' road design $(\mathrm{F}=0.83, \mathrm{p}=0.45)$ compared to the 'Less Complex' and 'Complex' roads designs $(F=0.74, p=0.48 ; F=0.15, p=0.87)$, respectively. The ANOVA results revealed that the complexity of road design affected senior driving behaviour. The complexity of the 'More Complex' scenario led senior drivers to cross road centrelines more often (mean=0.35, $\mathrm{SD}=1.48$ ) compared to the 'Less Complex' (mean=0.10, $\mathrm{SD}=0.30$ ) and 'Complex' (mean $=0.15, \mathrm{SD}=0.43$ ) ones. Poor turn manoeuvre at roundabouts and junctions were main factors of unsafe driving behaviour. DfT (2015b) confirmed that poor turn manoeuvre led drivers to road accidents.

\section{v. Road edge excursions}

Table 4 shows there is a low significant impact between the senior drivers' age group and road edge excursions; Simulation $1(F=0.56, p=0.57)$, Simulation $2(F=1.26, p=0.30)$, and 
Simulation $3(\mathrm{~F}=1.23, \mathrm{p}=0.31)$. The ANOVA test revealed that senior drivers crossed the road edge more frequently in the 'More Complex' scenario (mean=4.85, $\mathrm{SD}=1.12$ ) compared with the 'Less Complex' (mean=3.90, SD=2.32) and 'Complex' (mean=4.20, SD=1.44) scenarios. As similar to centreline crossings, poor turn manoeuvre affected senior drivers' safety which could lead to the risk of collisions. Senior drivers being likely to drive close to the kerb (e.g. to get a close view of traffic signs' information) was the reason for the highest mean value. Based on Table 4, the alternative hypothesis has been rejected and at the same time the null hypothesis was accepted at a significant alpha of 0.05 . The hypothesis states that there is a low impact between driving behaviour, and road safety on airport road access wayfinding design.

\section{DISCUSSION}

The paper suggests that driving simulation is useful for testing drivers' wayfinding ability in a virtual environment. The study investigated the impact of different wayfinding and signage provisions on driving behaviour in three groups aged 50 and over. ANOVA results showed that drivers' particular age group had a low impact between driving behaviour and road safety on airport road access wayfinding design. There are several contributory factors that may influence safe driving behaviour. To emphasize the driving simulation results, the preferred key factors leading to road accidents have been considered as shown in Table 5.

DfT (2015c) reported that road accidents involving fatalities of senior drivers have only fallen by 15 per cent from the years 2005 to 2009. However, road accidents that involved serious injuries rose 10 per cent over the same period. DfT reported that in the year 2000, people aged 60 or over accounted for about 20.8 per cent of Great Britain's population. By 2013, this had risen to 23 per cent, just over a 10 per cent increase. As the number of people in the senior age group increases, a higher number of road accidents involving senior drivers would be expected. In addition, as people get older their health condition becomes more infirm (Cuenen et al., 2016; National Institute on Aging et al., 2011). Thus, it could lead to problems such as poorer depth perception and an increase in mistakes in both cognitive and physical behaviour (Department for Transport, 2015c; Marin-Lamellet \& Haustein, 2015; National Institute on Aging et al., 2011; Oxley et al., 2006; RoSPA, 2010). These factors affected senior drivers' ability to focus on the road while driving to the airport. 
Table 5: Mapping of contributory factors influence safe driving behaviour

\begin{tabular}{|c|c|c|c|c|c|}
\hline Contributory Factors & $\begin{array}{c}\text { Risk to } \\
\text { collisions }\end{array}$ & $\begin{array}{c}\text { Speed } \\
\text { exceedances }\end{array}$ & $\begin{array}{c}\text { Traffic } \\
\text { light } \\
\text { tickets }\end{array}$ & $\begin{array}{c}\text { Centreline } \\
\text { crossings }\end{array}$ & $\begin{array}{c}\text { Road edge } \\
\text { excursions }\end{array}$ \\
\hline Failed to look properly & $\mathrm{X}$ & $\mathrm{X}$ & $\mathrm{X}$ & $\mathrm{X}$ & $\mathrm{X}$ \\
\hline Poor turn or manoeuvre & $\mathrm{X}$ & & & $\mathrm{X}$ & $\mathrm{X}$ \\
\hline $\begin{array}{c}\text { Failed to judge other } \\
\text { drivers' path or speed }\end{array}$ & $\mathrm{X}$ & $\mathrm{X}$ & & & \\
\hline Following too close & $\mathrm{X}$ & & $\mathrm{X}$ & $\mathrm{X}$ & $\mathrm{X}$ \\
\hline $\begin{array}{c}\text { Disobeyed 'Give Way' or } \\
\text { 'Stop' sign or markings }\end{array}$ & $\mathrm{X}$ & $\mathrm{X}$ & & $\mathrm{X}$ & $\mathrm{X}$ \\
\hline Loss of control & $\mathrm{X}$ & & $\mathrm{X}$ & $\mathrm{X}$ & $\mathrm{X}$ \\
\hline Travelling too fast & $\mathrm{X}$ & $\mathrm{X}$ & & $\mathrm{X}$ & $\mathrm{X}$ \\
\hline Swerved & $\mathrm{X}$ & & $\mathrm{X}$ & & \\
\hline Exceeding speed limit & $\mathrm{X}$ & $\mathrm{X}$ & $\mathrm{X}$ & $\mathrm{X}$ & $\mathrm{X}$ \\
\hline Aggressive driving & $\mathrm{X}$ & $\mathrm{X}$ & & \\
\hline
\end{tabular}

There are three major of driving simulation that affects the ease of driving orientation and wayfinding designs to the airport. Firstly, the sign design of driving scenario's should be distinctive and different (J. R. Harding et al., 2011). Airport 'directional arrow' sign should be bigger, bold text, different colour and symbol than other signs. The airport landside signs should be identical in term of size, colour and style to be compared with current motorway signs. The senior drivers could differentiate and signifies the airport signs while they are performing wayfinding. Therefore, it is very important that airport signs adhere to copy, styles and sizes, consistent terminology and symbols and uniform colours of basic guiding principles standard functions (AASHTO, 2010; J. R. Harding et al., 2011; Smiley et al., 2004). Message content should be easily understood by airport travellers. For instance, first time travellers require different information rather than frequent flyers. Secondly, some attributes in driving simulation can be seen from various viewpoints. For example, the 'Less Complex' scenario was developed with 'comfort' driving environment which allows drivers to view the routes and landmarks more easily and distinctively compared than other scenarios. Adding more to that, in some attributes of simulated driving such as 'More Complex' scenario, senior drivers require sign direction to be displayed as far as possible to the airport (AASHTO, 2010). Thirdly, as age increases, it is certain that general health and fitness will begin to deteriorate which leads to road accident risks. The senior drivers felt that their 
driving experience skills and driving abilities may not be as good as they once were (RoSPA, 2010). As a result, senior driver control their driving experience and develop a more defensive and cautious driving behaviour as they grow older. The senior drivers are commonly involved in collisions often because they misjudge the speed or distance of other vehicles or fail to see a hazard (Chevalier et al., 2016; Cuenen et al., 2016; Devlin \& McGillivray, 2016; National Institute on Aging et al., 2011). From the driving simulation results, it shows that the 'more complex' of road design makes wayfinding more difficult. For instance, the senior drivers made more errors in the 'more complex' scenario which led to risk of collisions, exceeding the speed limit, centreline crossings, and road edge excursions. Senior drivers are more likely to have more driving errors which leads to road accidents.

\section{CONCLUSION}

In conclusion, the study revealed that senior drivers' attention and ability to process signage and wayfinding information is limited. These limitations can create difficulties because driving requires the division of attention between control tasks, guidance tasks and navigational tasks. Drivers' attention can be switched rapidly from one wayfinding information source to another. This means that drivers only attend well to one source at a time. For instance, while driving to the airport, drivers can only extract a small proportion of the available information from the road scene (i.e. airport directional signs). Thus, to interpret a limited information processing capacity while driving, drivers can only determine acceptable information loads that they can manage (Mårdh, 2016). When drivers' acceptable incoming information load is exceeded, they tend to neglect other information based on level of importance (i.e. if driver was looking for the word 'airport' on the sign, they tend to neglect the speed limit signs). As with decision making of any sort, error is possible during this process (Casutt et al., 2014). Drivers were less focused on information that turns out to be important, while less important information was retained. In addition to information processing limitations, drivers' attention is not fully within their conscious control. For drivers with some degree of experience, driving is a highly-automated task. Driving can be performed while the driver is engaged in thinking about other matters. Most drivers, especially a frequent traveller to the airport or one familiar with the airport route, have experienced the phenomenon of becoming aware that they have not been paying attention during the last few miles of driving (e.g. airport staff). The less demanding the driving task, the more likely it is that the drivers' attention to the airport wayfinding and signage will wander, either through internal preoccupation or through engaging in non-driving tasks. Factors such as complexity of road design and environment or increased traffic congestion 
could also contribute to distracted driver's ability to keep track of wayfinding. Inattention may result in unintentional movements out of the lane, exceeding the speed limit (Chevalier et al., 2016) and failure to detect a vehicle on a conflicting path at an intersection (Dukic \& Broberg, 2012; Mårdh, 2016; Oxley et al., 2006) that exposed drivers to the risk of collisions and reduced road safety.

\section{LIMITATION}

Driving simulators have a few disadvantages. For instance, simulator sickness (a type of motion sickness) is experienced by senior drivers whilst "driving" in the simulator room; it may include dizziness, headache, nausea and vomiting (Mourant \& Thattacherry, 2000). Apparently, a senior driver would be compromised when experiencing these symptoms and it may not be appropriate for all drivers to be involved in a simulated driving experience. Gruening et al. (1998) claimed that the information gained through driving simulations may be misleading if the simulator does not provide an appropriate analogue to the simulated scenario, and that high reliability driving simulations are sometimes far more expensive than vehicle testing.

\section{FUTURE RESEARCH}

This research addressed the gaps in the literature on the airport road access wayfinding and the relationship between senior driving behaviour and road safety on airport road access wayfinding design. A driving simulator has been used as a tool to measure the relationship between these variables. In this section, further directions for future research are suggested. Firstly, Satellite Navigation (Sat Nav) was suggested to assess its impact on senior driving behaviour towards airport road access wayfinding. However, the Sat Nav was not built-in in the STISIM driving simulator Version 2. The idea of the insertion of Sat Nav as a tool to aid senior drivers to perform airport wayfinding hopefully would extend the current research, with additional variables on the impact of airport road access design using a simulated driving scenario. Secondly, senior drivers aged 50 years and over were chosen to participate in this research. Results from the simulated driving test were analysed and findings were measured only focusing on senior drivers attributes. It is suggested that this research could be extended to the younger drivers and with a consideration of gender to assess any effects on driving behaviour and road safety on the complexity of road design. 


\section{REFERENCES}

AASHTO. (2010). Chapter 2 - Human factors. In An introduction to highway safety manual (pp. 1-2). Washington: American Association of State Highway and Transportation Officials.

Alhussein, S. N. (2011). Analysis of ground access modes choice King Khaled International Airport, Riyadh, Saudi Arabia. Journal of Transport Geography, 196), 1361-1367.

Alsnih, R., \& Hensher, D. A. (2003). The mobility and accessibility expectations of seniors in an aging population. Transportation Research Part A: Policy and Practice, 3710), 903-916.

Ashford, N. J., Mumayiz, S., \& Wright, P. H. (2011). Airport Access. In Airport Engineering: Planning, Design, and Development of 21st Century Airports (Fourth Edi, pp. 543-572). Hoboken, NJ, USA: John Wiley \& Sons, Inc.

Beijer, D., Smiley, A., \& Eizenman, M. (2004). Observed driver glance behavior at roadside advertising signs. Transportation Research Record: Journal of the Transportation Research Board, 1899(1), 96-103.

Beins, B. C., \& McCarthy, M. A. (2012). Research methods and statistics. United States of America: Pearson.

Bhise, V. D., \& Rockwell, T. H. (1973). Development of a methodology for evaluating road signs. Development of a Methodology for Evaluating Road Signs. USA: Transportation Research Board.

Budd, T., Ison, S., \& Ryley, T. (2011). Airport surface access in the UK: A management perspective. Airport Management, 1(1), 109-117.

Burns, P. C. (1998). Wayfinding errors while driving. Journal of Environmental Psychology, $18(2), 209-217$.

Casutt, G., Martin, M., Keller, M., \& Jäncke, L. (2014). The relation between performance in on-road driving, cognitive screening and driving simulator in older healthy drivers. Transportation Research Part F: Traffic Psychology and Behaviour, 22, 232-244.

Chang, Y.-C. (2013). Factors affecting airport access mode choice for elderly air passengers. Transportation Research Part E: Logistics and Transportation Review, 57, 105-112.

Charles, M., \& Haddad, H. (2007). Prolonging the safe driving of older people through technology. Final report. Bristol: University of the West of England.

Chebli, H., \& Mahmassani, H. S. (2002). Air travelers' stated preferences towards new airport landside access mode services. In Annual Meeting of Transportation Research Board. 
Washington, D.C.

Chevalier, A., Coxon, K., Chevalier, A. J., Wall, J., Brown, J., Clarke, E., ... Keay, L. (2016). Exploration of older drivers' speeding behaviour. Transportation Research Part F: Traffic Psychology and Behaviour.

CrashMap. (2015). CrashMap - Public Access to Road Safety Data. Retrieved May 1, 2015, from http://www.crashmap.co.uk/.

Cuenen, A., Jongen, E. M. M., Brijs, T., Brijs, K., Lutin, M., Van Vlierden, K., \& Wets, G. (2016). The relations between specific measures of simulated driving ability and functional ability: New insights for assessment and training programs of older drivers. Transportation Research Part F: Traffic Psychology and Behaviour, 39, 65-78.

Darken, R. P., \& Sibert, J. L. (1996). Wayfinding strategies and behaviors in large virtual worlds. In Proceedings of the SIGCHI conference on human factors in computing systems (pp. 142-149). ACM.

Department for Transport. (2015a). Casualties involved in reported road accidents (RAS30) Statistical data set. Department for Transport.

Department for Transport. (2015b). Contributory factors for reported road accidents (RAS50) - Statistical data sets. Department for Transport.

Department for Transport. (2015c). Reported road casualties Great Britain: annual report 2014. National Statistics, Department for Transport.

Department for Transport. (2015d). Transport Statistics Great Britain: 2015. National Statistics, Department for Transport.

Devlin, A., \& McGillivray, J. (2016). Self-regulatory driving behaviours amongst older drivers according to cognitive status. Transportation Research Part F: Traffic Psychology and Behaviour, 39, 1-9.

Dukic, T., \& Broberg, T. (2012). Older drivers' visual search behaviour at intersections. Transportation Research Part F: Traffic Psychology and Behaviour, 15(4), 462-470.

Elander, J., West, R., \& French, D. (1993). Behavioral correlates of individual differences in road-traffic crash risk: an examination method and findings. Psychological Bulletin, 113(2), 279-94.

Evans, A. W. (2003). Transport fatal accidents and FN-curves: 1967-2001. London, United Kingdom. 
Findlay, C., \& Southwell, K. (2004). You just follow the signs: understanding visitor wayfinding problems in the countryside. Open Space: People Space. An international conference on inclusive environments (27-29 October 2004).

Fuller, G. (2002). The arrow - directional semiotics: wayfinding in transit. Social Semiotics, 12(3), 231-244.

Gayle, E. (2014, December 29). Planes, trains and automobiles: safety and statistics. Euronews.

Godley, S. T., Triggs, T. J., \& Fildes, B. N. (2004). Perceptual lane width, wide perceptual road centre markings and driving speeds. Ergonomics, 4オ(3), 237-256.

Gruening, J., Bernard, J., Clover, C., \& Hoffmeister, K. (1998). Driving simulation. In SAE Special Publications, v 1361, Feb, 1998, 980223, Vehicle Dynamics and Simulation. Citeseer.

Harding, J. (2012). How to tell if your airport has a wayfinding problem. Journal of Airport Management, 6(3), 231-242.

Harding, J. R., Alderman, J., Frankel, M. J., Elizer, M. J., Chrysler, S. T., Poe, C. M., ... Esch, T. (2011). Wayfinding and signing guidelines for airport terminals and landside, ACRP (Airport Cooperative Research Program), Report 52. Washington, D.C.: Transportation Research Board of the National Academies.

Hassan, H., King, M., \& Watt, K. (2015). The perspectives of older drivers on the impact of feedback on their driving behaviours: A qualitative study. Transportation Research Part F: Traffic Psychology and Behaviour, 28, 25-39.

IAM. (2010). Older drivers - safe or unsafe? Institute of Advanced Motorists. London, United Kingdom.

Jamson, A. H., \& Merat, N. (2005). Surrogate in-vehicle information systems and driver behaviour: effects of visual and cognitive load in simulated rural driving. The Relationship between Distraction and Driving Performance: Towards a Test Regime for in-Vehicle Information Systems In-Vehicle Information Systems, 8(2), 79-96.

Kowal, P. K., Rao, P. V. C., \& Mathers, C. (2003). Information needs for research, policy and action on ageing and older adults. World Health Organization.

Mårdh, S. (2016). Identifying factors for traffic safety support in older drivers. Transportation Research Part F: Traffic Psychology and Behaviour, 38, 118-126.

Marin-Lamellet, C., \& Haustein, S. (2015). Managing the safe mobility of older road users: 
how to cope with their diversity? Journal of Transport \& Health, 2(1), 22-31.

May, A. J., Ross, T., \& Bayer, S. H. (2005). Incorporating landmarks in driver navigation system design: an overview of results from the regional project. Journal of Navigation, $58(1), 47-65$.

Mitchell, M. (2010). An analysis of road signage and advertising from a pragmatic visual communication perspective: case study of the M1 motorway between the Gold Coast and Brisbane. Journal of the Australasian College of Road Safety, 21(2), 55.

Montello, D. R., \& Sas, C. (2006). Human factors of wayfinding in navigation.

Mourant, R. R., \& Thattacherry, T. R. (2000). Simulator sickness in a virtual environments driving simulator. In Proceedings of the Human Factors and Ergonomics Society Annual Meeting (Vol. 44, pp. 534-537). SAGE Publications.

National Institute on Aging, National Institutes of Health, \& U.S. Department of Health and Human Service. (2011). Global health and ageing. World Health Organization. World Health Organization.

O'Hern, S., \& Oxley, J. (2015). Understanding travel patterns to support safe active transport for older adults. Journal of Transport \& Health, 2(1), 79-85.

Oltedal, S., \& Rundmo, T. (2006). The effects of personality and gender on risky driving behaviour and accident involvement. Safety Science, 44(7), 621-628.

Orimo, H., Ito, H., Suzuki, T., Araki, A., Hosoi, T., \& Sawabe, M. (2006). Reviewing the definition of "elderly." Geriatrics and Gerontology International, 6(3), 149-158.

Oxley, J., Fildes, B., Corben, B., \& Langford, J. (2006). Intersection design for older drivers. Transportation Research Part F: Traffic Psychology and Behaviour, 9(5), 335-346.

Raubal, M. (2001). Human wayfinding in unfamiliar buildings: a simulation with a cognizing agent. Cognitive Processing, 2(3), 363-388.

Raubal, M., \& Egenhofer, M. J. (1998). Comparing the complexity of wayfinding tasks in built environments. Environment and Planning B, 25, 895-914.

Raubal, M., \& Worboys, M. (1999). A formal model of the process of wayfinding in built environments. Spatial Information theory.Cognitive and Computational Foundations of Geographic Information Science, 748.

Robson, C., \& McCartan, K. (2016). Real World Research. Wiley (4th ed.). West Sussex, United Kingdom. 
RoSPA. (2010). Older drivers. The Royal Society for the Prevention of Accidents.

Sekaran, U. (2003). Research Methods for Business (Vol. Fourth edi). United States of America: John Wiley \& Sons, Inc.

Smiley, A., Houghton, J., \& Philp, C. (2004). Highway signing for drivers' needs. In Transportation Association of Canada (TAC) annual conference and exhibition. Québec, Canada.

Tam, M. L., Lam, W. H. K., \& Lo, H. P. (2008). Modeling air passenger travel behavior on airport ground access mode choices. Transportmetrica, 4(2), 135-153.

Transport Scotland. (2006). Road furniture in the countryside. Transport Scotland.

Wener, R. E., \& Kaminoff, R. D. (1983). Improving environmental information effects of signs on perceived crowding and behavior. Environment and Behavior, 15(1), 3-20.

WHO. (2016). Definition of an older or elderly person. Retrieved April 16, 2014, from http://www.who.int/healthinfo/survey/ageingdefnolder/en/. 